\title{
THE READING COMPREHENSION OF GRADE 5 SETSWANA- SPEAKING LEARNERS IN RURAL SCHOOLS IN SOUTH AFRICA: DOES HOME LANGUAGE MATTER?
}

Munyane Mophosho, Katijah Khoza-Shangase and Lesedi L. Sebole, University of the Witwatersrand

\begin{abstract}
The main aim of the study was to determine the reading comprehension performance of Grade 5 Setswana-speaking children in a rural province in South Africa, where the language of learning and teaching (LoLT) is English. Thirty-four Grade 5 learners from one province and from the same socio-economic background were selected through purposive sampling. The research design adopted was non-experimental, descriptive and quantitative in nature. Participants were required to perform reading comprehension tasks in English and Setswana. Four stories were utilised from the reading comprehension subtest of the GORT-4 ${ }^{\mathrm{TM}}$ Test Form A. Two of the stories from the test were administered on completion of the English reading comprehension task. The other two stories were translated and adapted into Setswana. The mean raw scores of results obtained were calculated and comparisons at different levels were performed using t-tests.

Results revealed poor overall reading comprehension scores in both languages; with scores below 55\%. Furthermore, current results indicated better performance in Setswana reading comprehension, with higher scores obtained in the difficult Setswana story than in English. These findings were statistically significant ( $p<.05)$. Implications of the influence of home / first language on reading comprehension, if the LoLT is not the learner's first language, are raised.
\end{abstract}

Key words: language, learning, multilingualism, reading comprehension, rural, schools, Setswana, teaching.

\section{INTRODUCTION}

Language competence and proficiency are essential for educational success (Bashir, Conte \& Heerde, 1998; Owens, 2004). Language proficiency focuses on the ability of an individual to communicate effectively in conversation, with (said) oral language used as a subset of language proficiency (Watts-Taffe \& Truscott, 2000). According to Cummins (2000), language proficiency includes proficiency in academic and social language. Academic language proficiency looks at "the extent to which an individual has access to and command of the oral and written academic registers of schooling" (Cummins, 2000: 67). This proficiency is not acquired as a natural skill, but develops through exposure to formal education (Cummins, 2000). Therefore, this indicates that for academic language competence to develop, explicit teaching strategies to address concepts and vocabulary implicit in the subject matter of different learning areas should be employed by educators (Bartolome, 1998). 
For learners to function successfully at school, they need to develop Basic Interpersonal Communication Skills (BICS), as well as the Cognitive Academic Language Proficiency (CALP) which is essential for language skills (Cummins, 1999). This distinction of BICS/CALP in language proficiency, has evolved to include "discrete language skills" (Cummins, 2001). Discreet language skills include “...the learning of rule governed aspects of language (including phonology, grammar and spelling)..." (Cummins, 2008). According to Cummins (1999), BICS refers to the learner's ability to master language at an oral level, allowing them to cope with day-to-day interactions, while CALP focuses on the advanced use of language; specifically, the ability to engage with language on a more challenging academic level. For effective second language learning to occur, children need to adequately develop CALP in their first language; allowing skills transfer from first language to second language. In South Africa, policy regarding language-in-education is that children's home language needs to be maintained; that teaching occurs in the child's home language, with access to a second language, mainly English, which ultimately becomes the language of learning and teaching (LoLT) in Grade 4 (Gardiner, 2008). According to the National Curriculum Statement (2002), during the transition phase from second language to English LoLT, the home language continues to be used with English for as long as possible.

This recommended smooth transition is challenging in a multilingual country like South Africa, which is a former colony (De Sousa, Greenop \& Fry, 2010). Because of this country's nature, there have been questions about how a person's language learning impacts on their academic language skills. This has led to many studies being conducted (Cummins, 1999; Lekgoko \& Winskel, 2008; De Sousa, et al., 2010) that indicated a complex relationship between first and second language, and how these influence each other. Such studies are important within the South African context where English is a LoLT, although it is not the home language of the majority of the population.

Statistics South Africa (2018) estimates the country's population at 57.7 million people, with a diversity of cultures, languages, religions, nationalities and ethnicities spread across nine provinces, with $80.2 \%$ of people being Black African. A majority speak IsiZulu $(23.8 \%)$ as a home language, with Setswana being spoken by $8.2 \%$. Evidence indicates that not many people use English $(9.6 \%)$ as a home language, regardless of its consideration as the language of commerce and science (Statistics South Africa, 2018).

English is the LoLT in many schools in South Africa, although few use it as a home language. The perception of the language being used and the status associated with the language are influential factors associated with choosing English-medium schooling, as opposed to basing the choice on home language (De Wet, 2002). The Language in Education Policy (1997) is the guiding force in determining the use of languages in the education system, and this policy promotes the learning of more than one language. The Revised National Curriculum Statement (2002) recognises the importance of a learner's home language, stating that it should be developed and maintained while learning an additional language. Competence in both languages is essential, and this manifests when the learner can use both languages academically and in day-to-day interactions (National Curriculum Statement, 2002). The results of this merit investigation.

Various studies show the difficulties faced by both learners and teachers regarding instruction in a second language. Minimal emphasis has been put on conducting research 
that specifically focuses on reading and reading comprehension, particularly in the field of Speech-Language Pathology where the current study was based. Pretorius and Ribbens (2005) acknowledge the lack of national assessment procedures for monitoring reading and determining learners' literacy levels. In 2006, about 30000 Grade 4 and 5 South African learners participated in the Progress in International Reading Literacy Study (PIRLS), which revealed the poor literacy levels of South African learners, ranking last of 40 countries that took part. Recently, South Africa was placed last out of 50 countries in the PIRLS which included nearly 320,000 children globally. The survey also found that reading scores have not improved since 2011 (Howie et al, 2016).

According to Cummins (1991), deficits in a child's first and second language will be evident if they are expected to use the second language exclusively, and if CALP has not fully developed through reading and writing in their first language. This author asserts that the level of competence in the second language will be so poor that it will be an ineffective mode of learning. Thus, successful learning of a second language is said to be aided by significant knowledge development in a first language; by transferring first language skills to the second language (Cummins, 1991). In addition, having metalinguistic skills, phonological processes, lexical ability, working memory and automaticity are also pivotal for literacy acquisition. In a study by Wilsenach (2013) where Northern Sotho learners in Foundation phase had phonological skills tested, it was concluded that literacy acquisition depends less on the nature of language instruction, but more on the development of metalinguistic and cognitive processes such as phonological awareness.

In the learning context, reading allows readers independent access to information, and also affords readers a powerful learning tool enabling them to construct meaning and acquire knowledge (Pretorius, 2002). Reading is essential for success in the learning process, and successful learning results in academic excellence. Essentially, successful learning is rooted in the individual's ability to integrate new information with already existing knowledge, leading to expanding and modifying their knowledge (Pretorius, 2000). The same principle applies in effective reading comprehension, where new reading information is integrated with existing knowledge in memory, thus cementing the relationship between effective reading and school success (Pretorius, 2000). The National Reading Panel (2000) described reading as a complex task requiring coordination of many cognitive processes such as recognising words, constructing meaning from sentences, and retaining what was read in memory.

Reading comprehension is a complex ability that requires mastering a number of skills which include decoding, fluency, vocabulary, sentence construction, reasoning and background knowledge, as well as working memory and attention, and these are complicated further by language. Research has shown that in order for children to be successful in acquiring and mastering a second language, they need to first master thinking and functioning in their home language, up until they reach academic language proficiency, before transitioning to using a second language (Meneghetti, Carretti \& DeBeni, 2006). This highlights that optimal development of a learner's home language is critical for transitioning into a second language. Therefore, a learner's home language is an important factor in determining academic success, specifically in reading comprehension, which is the focus of this study. Jordaan (2008) highlights that reading comprehension assists in language acquisition and that reading language and cognitive development go hand in hand. Learners in a South African context learning to read in a second language 
are required to decode the text quickly and accurately (Linan-Thompson \& Ortiz, 2009). They must also depend on contextual clues in order to read a large number of highfrequency words and identify unfamiliar words (Hulme \& Joshi, 1998).

For second language readers to reach an understanding of written text, they rely on various skills and strategies; combining background knowledge, real-world knowledge, vocabulary knowledge, and first language-related knowledge (Constantinescu, 2007). Bialystok (2001) highlights that the difficulty of the text and the learners' knowledge of the cultural and discourse conversations of the second language, influence successful reading comprehension. Second language readers' ability to read fluently is compromised by unfamiliarity of the vocabulary used in the text, the difference of English syntax from that of their first language, and the process of translating the text into their first language to help with understanding unfamiliar and challenging words (Linan-Thompson \& Ortiz, 2009).

According to Pretorius (2000), the poor reading ability of learners in South Africa is an underpinning characteristic of widespread academic underperformance at primary, secondary and tertiary levels. The PIRLS reports highlight a very important reality about how children in South African schools are performing in reading tasks (Mullis, Martin, Kennedy \& Foy, 2007; Howie et al., 2008, Howie et al., 2016). South African children performed poorly, despite the testing process and instructions being done in all 11 official languages. This raises many questions about the education system and factors contributing to the development of reading abilities in South African learners.

Factors identified as contributing to the development of reading abilities include, but are not limited to:

- location and availability of centres for learning which includes libraries, resource centres as well as schools (Pretorius, 2000; De Vries \& Van der Merwe, 2004);

- how much reading is emphasised in school curriculums and in the schools themselves;

- how much time is devoted to reading in schools;

- the availability of reading materials for learners;

- class organisation in terms of the number of learners in the class, as well as teacher-learner and learner-learner interactions in the class;

- methods used for reading in class such as reading aloud, independently, and in groups;

- methods used for assessing reading progress;

- roles of principals in facilitating effective learning;

- communication between teachers and parents;

- attendance levels of both learners and teachers;

- parental involvement in children's academic life;

- parental reading abilities and attitudes;

- language spoken at home and exposure to the LoLT;

- learners' attitudes towards reading;

- the age of learners when they begin school;

- previous exposure to reading (Mullis et al., 2007; Howie et al., 2008); and

- level of education and training of teachers for teaching reading (Nel \& Muller, 2010). 


\section{METHODOLOGY}

The main aim of the study was to determine the reading comprehension performance of Grade 5 Setswana-speaking children in a rural school in South Africa's North-West Province, where the LoLT is English.

Secondary aims were:

- to establish performance in an English reading comprehension task;

- to establish performance in a Setswana-translated reading comprehension task;

- to compare the groups' performances in these two comprehension tasks.

\section{Research design}

A non-experimental, quantitative and descriptive design was adopted (Schiavetti \& Metz, 2002). No manipulation of variables was carried out and no experimentation was conducted. A within-individual design was employed, focusing on all the participants taking part in all the testing procedures (Creswell, 2012). A repeated measures design was utilised with each participant taking part in the Setswana reading comprehension task and the English reading comprehension task.

\section{Participants}

Data were collected from two rural schools. The two schools were situated in the same geographical area. All learners where consent and assent were obtained were included in the study. A sample of 34 Grade 5 learners was included in the study, with 17 learners coming from each school. Each learner took part in both English- and Setswana-reading tasks.

All participants were in a rural primary school, using Setswana as a home language and English as a LoLT. No underlying sensory, cognitive, physical or psychological concerns that may present as confounding variables in the study were present.

\section{Sampling procedure}

Prior to commencement of the study, approval was obtained from all relevant stakeholders, with consent secured from the school principals and parents/legal guardians of the learners who participated. Assent was also obtained from each learner.

\section{Instruments}

The Gray Oral Reading Tests-4 (GORT-4 ${ }^{\mathrm{TM}}$ ) was used in conducting the study. It is appropriate to use with individuals between the ages of 6 to 18 years; hence its appropriateness for the current study of Grade 5 learners. This test has been reported to be an appropriate measurement tool that provides an objective measure of oral reading growth and an aid in the diagnosis of oral reading difficulties. The test can also be used to measure change in oral reading levels over time (Wiederholt \& Bryant, 2001). It is acknowledged that because this test was normed in North America, it may have limitations within the South African context, hence the importance of piloting the tool which was conducted in the current study. 
The GORT $-4^{\mathrm{TM}}$ has two parallel forms, Form A and Form B, each containing 14 separate reading texts. Form A was used in this study. The GORT-4TM assesses rate (time taken to read the text), accuracy (ability to pronounce the words in the text), fluency (combined scores of rate and accuracy) and comprehension (correct scores given to questions on each text) of an individual; and this gives an indication of overall reading ability (Wiederholt \& Bryant, 2001). The reading comprehension scores of the test were used in the study.

Four reading texts from Form A were utilised, two of which were translated and adapted to Setswana. Adaptations were also made to the two stories that were utilised during the English reading task to make the stories culturally and contextually appropriate. This was done with the assistance of two expert speakers of Setswana from the Linguistics Department of the University of the Witwatersrand. This was back-translated by another expert speaker to evaluate any changes in the test. This evaluation found that the test did not differ from the original. Barratt, Khoza-Shangase and Msimang (2012) state that translating and adapting a test is a critical process that needs to take into account the personal characteristics of individuals translating the test, which will have an effect on how the test is translated. These authors raise caution against any inappropriateness of vocabulary and sentence structures, which they argue are some of the factors that may dilute the complexity of the translated material. The two stories that were used in the Setswana reading comprehension task were piloted to ensure reliability and validity (Mertens, 2005).

\section{Data collection}

Each learner was tested individually in a quiet room, where they completed the reading comprehension tasks in both languages. Each task included reading two stories, one 'easy' and the other 'difficult'. In each story, learners were given a score of 1 for each correct answer. Each story had five multiple-choice questions that each learner had to answer. Each answer was recorded on the score sheet.

\section{Ethical considerations}

Data collection commenced following ethical approval from the relevant supervisory authority at the University's Ethical Committee (Medical) (protocol number: H120411) as well as from the relevant hospitals' authorities. Once approval was secured, data collection commenced after assent was secured from each learner. All ethical considerations were observed. Ethical considerations were based on the Nuremberg Code of Ethics, the World Medical Associations (WMA) Declaration of Helsinki and the Belmont Report on ethical treatment of research participants.

\section{Reliability and Validity}

The GORT-4TM is reported to be between $86 \%$ and $96 \%$ reliable, specifically the comprehension-scoring of Form A. This indicates good reliability (Wiederholt \& Bryant, 2001). Inter-examiner reliability was achieved by two examiners scoring the test while one examiner administered it for $40 \%$ of the learners in the sample (Hedge, 2003). GORT-4 validity was measured in terms of content, criterion, prediction, and construct validity. Evidence revealed that the test is valid and therefore appropriate to use (Wiederholt \& 
Bryant, 2001). Validity of the stories used in the Setswana task was determined by piloting the tests.

\section{DATA ANALYSIS}

Mean raw scores and totals were calculated for each story for both Setswana and English stories. Statistical comparisons included between-group comparison using independent sample t-tests, within-group comparison of the scores obtained from the two stories (Story 1 and 2) in Setswana and English using paired sample t-tests, and comparison between the total Setswana and English scores, also using paired sample t-tests. The fixed value for the level of significance used in the study was 0.05 (5\%) (Chiang, 2003).

\section{RESULTS AND DISCUSSION}

The main aim of the study was to determine reading comprehension abilities in Grade 5 Setswana-speaking learners in rural schools where English is used as the LoLT. The focus was on comparing performance in Setswana and English. The results of the study are presented in the following sequence: overall results of the learners in each school, comparisons between the two schools and, finally, comparison between Setswana and English comprehension scores of the two schools combined.

Table 1 presents mean scores obtained for each comprehension task in Setswana and English, as well as the mean total of scores for tasks in Setswana and English for each school.

Table 1: Mean raw scores and percentages obtained by the learners for each comprehension task in Setswana and English for each school

\begin{tabular}{lllllll} 
& Setswana & & & English & \\
& Story 1 & Story 2 & Total & Story 1 & Story 2 & Total \\
\hline $\begin{array}{l}\text { Total } \\
\text { possible }\end{array}$ & 5 & 5 & 10 & 5 & 5 & 10 \\
\hline School A & 2.18 & 2.53 & 4.71 & 2.18 & 1.71 & 3.88 \\
& $(43.6 \%)$ & $(50.6 \%)$ & $(47.1 \%)$ & $(43.6 \%)$ & $(34.2 \%)$ & $(38.8 \%)$ \\
\hline School B & 1.65 & 1.71 & 3.35 & 1.94 & 0.82 & 2.76 \\
& $(33 \%)$ & $(34.2 \%)$ & $(33.5 \%)$ & $(38.8 \%)$ & $(16.4 \%)$ & $(27.6 \%)$ \\
\hline Total & 1.91 & 2.12 & 4.03 & 2.06 & 1.26 & 3.32 \\
& $(38.2 \%)$ & $(42.4 \%)$ & $(40.3 \%)$ & $(41.2 \%)$ & $(25.2 \%)$ & $(33.2 \%)$ \\
\hline
\end{tabular}

Learners from both schools performed poorly (below 55\%) in all tasks, with school A scoring higher $(50.6 \%)$ in the Setswana Story 2 task. Although learners performed poorly in both languages, performance in Setswana was better than in English. The overall poor performance is consistent with research indicating that learners in South African schools perform poorly in reading tasks (Mullis, Martin, Kennedy \& Foy, 2007; Howie et al, 2008; Pretorius 2000, Pretorius, 2002; Wildschut, Moodley \& Aronstam, 2016). Several factors have been identified as contributing to low levels of reading ability, including but not limited to how much reading is emphasised in the curriculum; proficiency of teachers in teaching English second language learners and the language itself; languages used by learners; time devoted to learning; preparation of learners on learning how to read; 
learners' attitudes towards reading, as well as limited numbers of libraries in the schools (Mullis et al, 2007; Nel \& Muller, 2010; Howie et al, 2008; Pretorius, 2000; Van Staden \& Bosker, 2014; Wildschut, Moodley \& Aronstam, 2016). The higher scores in Setswana found in this study align with evidence suggesting that use of the first language as LoLT yields better outcomes (Mabiletja, 2015; Cummins, 2006; Makalela, 2005).

\section{Between-group comparisons}

Results of the independent sample t-tests comparing learners' scores in both schools are presented in Table 2 below.

Table 2: Results of two sample t-tests showing comparisons between the learners in both schools on each measure

\begin{tabular}{lllllll}
\hline & Setswana & & & English & \\
& Story 1 & Story 2 & Total & Story 1 & Story 2 & Total \\
score & & & & Score \\
p-value & 0.25 & 0.09 & 0.1 & 0.61 & 0.65 & 0.15 \\
\hline
\end{tabular}

While the mean scores in Table 1 indicate that school A performed worse than school B on all measures, with school A obtaining $50.6 \%$ for the Setswana Story 2 task, Table 2 indicates no significant difference between the scores obtained by the learners on any of the measures. The data for the two schools can be combined into one data set. The absence of statistical difference between the two schools may be attributed to learners in schools coming from the same socio-economic background, being Setswana first-language speakers, being exposed to English as the LoLT, and attending government (public) schools that use the same teaching methods with access to similar resources.

\section{Within-group comparisons}

The results of the paired sample t-tests comparing the scores obtained by the learners in each school for on each text and on the total scores in Setswana and English are presented in Table 3.

Table 3: Results of paired sample t-tests (p-values) showing comparisons between mean scores for Setswana and English texts within each school

\begin{tabular}{llll}
\hline & Setswana & English & \\
& $\begin{array}{l}\text { Comparisons between } \\
\text { Story 1 \& 2 }\end{array}$ & $\begin{array}{l}\text { Comparisons between } \\
\text { Story 1 \& 2 }\end{array}$ & $\begin{array}{l}\text { Comparisons between } \\
\text { Setswana \& English } \\
\text { total scores }\end{array}$ \\
School A & 0.33 & & 0.13 \\
School B & 0.84 & 0.15 & 0.34 \\
\hline
\end{tabular}

**significant at $5 \%$ level

Results in Table 3 indicate that there is no statistically significant difference between the scores for Story 1 and 2 in Setswana in either school. The difference between the total scores in Setswana and English was also not significant in either school. There was a significant difference noted in school B when comparing the scores for on Story 1 and Story 2 in English. This is attributed to this group obtaining a significantly higher mean 
score for Story $1(1.94 / 5)$ than for Story $2(0.82 / 5)$. Story 1 was the 'easy' story and Story 2 a 'difficult' story, thus these scores reflect expectations.

The results of the paired sample t-tests comparing the combined scores are presented in Table 4 below.

Table 4: P-values for paired sample t-tests showing comparisons of the combined results.

\begin{tabular}{ll} 
Specific comparisons & p-value \\
Comparing Story 1 \& Story 2 in Setswana & 0.37 \\
Comparing Story 1 \& Story 2 in English & $0.001 * *$ \\
Comparing Setswana Story 1 \& English Story 1 & 0.59 \\
Comparing Setswana Story 2 \& English Story 2 & $0.002 * *$ \\
Comparing total Setswana \& English scores & 0.078 \\
\hline
\end{tabular}

**Significant at the $5 \%$ level

The results indicate that there is no significant difference between the comprehension task scores for Story 1 and Story 2 in Setswana, indicating that the participants did not find one story more difficult than the other. The results obtained may be attributed to numerous factors, including the learners' background knowledge, the language used in the text (home language), and the learners possessing an extensive vocabulary in their home language. However, there was a significant difference noted between the scores for Story 1 and Story 2 in English, with the learners obtaining a higher mean score in Story $1(2.06 / 5)$ than they did in Story $2(1.26 / 5)$. This reflects the significant difference in the scores obtained by the learners in School B. With Story 1 as 'easy' and Story 2 as 'difficult', these differences were anticipated.

There was no significant difference between the scores for Setswana Story 1 comprehension tasks (1.91/5) and English Story 1 comprehension tasks (2.06/5), indicating that the learners did not comprehend significantly better in either language when the stories were regarded as easy. However, a significant difference was noted when comparing the scores for Setswana Story 2 and English Story 2 comprehension tasks, with the learners obtaining a higher mean score on the Setswana measure $(2.12 / 5)$ than they did on the English measure (1.26/5). This suggests that the learners comprehended better in Setswana than in English when the stories are difficult.

No significant difference between the overall Setswana (4.03/10) and English (3.32/10) reading comprehension scores was found, implying that, in this sample, the reading abilities of the learners in Setswana and English were similar. This was despite the fact that one language (Setswana) is considered the home language of the learners, thus having developed earlier than the LoLT (English). The fact that this only happened when the scores were combined is important to note; and yet, when separated by a level of complexity, the findings favoured Setswana. According to Cummins (1991; 2005), a deficit in a learner's first and second language will be evident if the learner is expected to use the second language exclusively, if CALP has not fully developed in their first language through reading and writing, and if the level of competence in the second language is too poor for it to be an effective mode of learning. In the current study, the overall poor reading abilities observed indicate that adequate development in the learners' first language had not yet occurred, yet they are expected to acquire these skills in the 
second language, which is their LoLT. This negatively influences their opportunities for consolidating their first language skills crucial for success in reading comprehension. This, consequently, affects the development of the second language, which results in difficulties in language-related tasks in both languages.

These findings support research by Probyn (2001) and Bloch (2002) which revealed that teaching and learning delivered in learners' second language can be challenging for learners who do not have the LoLT as first language. The difficulty in these settings could be due to limited and inappropriate models of teaching and learning. Most educators and learners in this rural province are not home-language speakers of the LoLT. Probyn (2005) argues that there exists a lack of appropriate and successful transference of language policies into classroom practice. For example, teachers and learners code-switch where both teacher and learner speak the same first language, which negatively impacts on the exposure and consolidation of the second language, which in this case is English; which also serves as the LoLT (Probyn, 2005).

These findings have important implications for the development of reading comprehension skills in multilingual contexts. Consolidation of first language development for learning and teaching is integral - regardless of whether the LoLT is the first or second language of the learner. It can also be argued that these findings propose that irrespective of the language of instruction, reading skills and comprehension processes should be taught if literacy levels of the children in South Africa are to be improved. Reading's complexity requires coordination of many cognitive processes, such as recognising words, constructing meaning from sentences and retaining what was read in one's memory (Afflerbach, Pearson \& Paris, 2008). For these cognitive processes to develop, external facilitation, effective teaching by educators, provision of resources, as well as provision of support by the Department of Basic Education to learners and teachers is necessary. Factors identified as contributing to the development of reading abilities (Pretorius, 2000; De Vries \& Van der Merwe, 2004; Mullis et al., 2007; Howie et al., 2008; Nel \& Muller, 2010) need to be addressed in order to improve the poor literacy levels observed and the poor reading comprehension skills found in the current study.

\section{CONCLUSION}

Our conclusions are based on children performing particularly poorly from these schools on a portion of the GORT- $4^{\mathrm{TM}}$, thus these findings are not particularly robust. These findings are also not easily interpretable without independent measures of the children's oral language abilities in English and Setswana. These current findings are preliminary.

Reading comprehension is a complex, high cognitive function which requires one's cognition to be functioning well in order for one to comprehend what is written. Cognitive development is linked to language development, and ignoring the influence of the first language of learners when selecting LoLT could be detrimental to the academic proficiency of learners (Cummins, 2008). Nyika's (2015) work on basic education and later levels of learning shows that one of the key factors contributing to poor performance of indigenous students at university in developing countries is the use of a second language as the language of instruction. Professionals working with learners need to understand and take into account the fact that most learners attending public schools in South Africa are multilingual, so when addressing reading comprehension, teachers need to consider the learners' home language and LoLT, as well as other factors that play a role in influencing 
reading. Factors such as culture, environment, and availability of resources to the learner. The influences that first language and second language have on one another are major factors that need to be interrogated in South Africa, where multilingualism is more common than bilingualism (Makalela, 2016). Most public schools in South Africa use English as the primary medium of instruction and the learners are taught and tested in English. Research has shown that in order for a learner to be proficient in a second language, they need to have solid grounding in their first language and be taught discrete language skills such as phonology, grammar, and spelling (Cummins, 2008; Wilsenach, 2013; Le Roux, et al., 2017).

These research findings have important implications for South African educators, schools' managements, and speech-language therapists whose caseloads comprise of mainly English second language speakers. To ensure efficacious assessments and management of these clients, careful deliberation on the impact of multilingualism and multiculturalism within this context is required. Collaboration between teachers and speech-language therapists is an essential process that can ensure that English second language learners are afforded appropriate instruction to better facilitate English language development and to improve their academic skills (Linan-Thompson \& Ortiz, 2009), while language policies are critically evaluated (e.g. English as LoLT). The fact that participants in the current study were children at primary school level whose language proficiency was still developing in their first language, and who had not yet developed language proficiency in their additional languages, emphasised the influence of development in their ability to decode and read for understanding. Policy-makers need to carefully deliberate on the influence of LoLT in basic education as part of the early childhood development initiatives aimed at ensuring successful intervention. Programmes such as The National Reading Strategy (2008), which aim to improve the reading competence of learners, need to take cognisance of the multilingual and multicultural nature of the South African society. Reading comprehension in the curriculum needs to be emphasised, as it is an intricate skill to acquire. The poor reading comprehension scores found here highlight the realities of many schools in South Africa; that of learners' low reading levels which need urgent attention to find ways to improve them. Potentially, teachers' skills can be improved for more successful teaching and learning. Nel and Muller (2010) highlight that the level of education and training of teachers for teaching reading needs to be addressed, as it is crucial for learners' success in reading.

Current findings should be interpreted taking cognisance of the identified methodological limitations of the study. Firstly, the results of the study cannot be readily generalised to all Grade 5 learners with Setswana as their first language with English-LoLT, as only two schools were included in the study. Secondly, learners in the study also shared similar socio-economic backgrounds and the schools were rural. Thirdly, the study involved 34 participants and, according to Mertens (2005), a larger sample size is preferred as it has less variability and provides stronger statistical significance. Nonetheless, these limitations raise implications for future research.

\section{REFERENCES}

AFFLERBACH, P, PD PEARSON \& SG PARIS. 2008. "Clarifying Differences Between Reading Skills and Reading Strategies". The Reading Teacher, 61 (5): 364-373. 
BARTOLOME, L. 1998. The Misteaching of Academic Discourse: The Politics in the Language Classroom, Boulder, CO: Westview Press.

BARRATT, J, K KHOZA-SHANGASE \& J MSIMANG. 2012. "Speech-language assessment in a linguistically diverse setting: Preliminary exploration of the possible impact of informal 'solutions within the South African context'. South African Journal of Communication Disorders, 59 (1): 34-44.

BASHIR, A, BM CONTE \& SM HEERDE. 1998. Language and school success: Collaborative challenges and choices. In Merritt, D \& B Culatta (Eds), Language intervention in the classroom, San Diego: Singular.

BIALYSTOK, E. 2001. Bilingualism in development: language, literacy and cognition. Cambridge: Cambridge University Press.

BLOCH, C. 2002. Concepts of early childhood development (ECD) literacy learning and materials development in multilingual settings - Occasional Paper No. 8. Cape Town: PRAESA.

CHIANG, CL. 2003. Statistical Methods of Analysis. DOI: 10.1142/5224

CONSTANTINESCU, A I. 2007. "Using technology to assist in vocabulary acquisition and reading comprehension". The Internet TESL Journal, 13 (2): 65-87.

CRESWELL, JW. 2012. Educational research: Planning, conducting and evaluating quantitative and qualitative research $\left(4^{\text {th }} \mathrm{ed}\right)$, Boston: Pearson Education.

CUMMINS, J. 2008. BICS and CALP: Empirical and Theoretical Status of the Distinction. In Street, B \& NH Hornberger (Eds). Encyclopedia of Language and Education, $2^{\text {nd }}$ Edition, volume 2: Literacy. New York: Springer Science + Business. (pp. 71-83).

CUMMINS, J. (2006). How long does it take for an English language learner (ELL) to become proficient in a second language? In Freeman, R \& E. Hamayan (Eds.) Educating English Language Learners: A Guide for Administrators Philadelphia: Caslon. (60-61).

CUMMINS, J. (2005). Education in a multilingual society. In. K. Brown (Ed.). The Encyclopedia of Language and Linguistics. 2nd Edition. Oxford: Elsevier Ltd.

CUMMINS, J. (2001). Negotiating identities: Education for empowerment in a diverse society (2nd ed.). Los Angeles: California Association for Bilingual Education.

CUMMINS, J. 2000. Language, power and pedagogy: Bilingual children in the crossfire. Clevendon: Multilingual Matters, Ltd.

CUMMINS, J. 1999. BICS and CALP: Clarifying the distinction, (ERIC) Education Resources Information Centre ED 438551.

CUMMINS, J. 1991. Interdependence of first and second-language proficiency in bilingual children, in Bialystok, E (Ed), Language processing in bilingual children, Cambridge: Cambridge University Press, 70-89.

DE SOUSA, D S, K GREENOP \& J FRY. 2010. "The effects of phonological awareness of Zulu-speaking children learning to spell in English: A study of cross-language transfer". British Journal of Educational Psychology, 80(4): 517-533.

DEPARTMENT OF EDUCATION OF SOUTH AFRICA. 2002, Revised National Curriculum Statement Grades R-9. Available from http://www.education.gov.za/Curriculum/pdf. [Accessed: 3 July 2012]

DE VRIES, LC \& R VAN DER MERWE. 2004. "School libraries in the Northern Cape Province - where do we stand?" South African Journal of Libraries and Information Science, 70 (2): 121-131. 
DE WET, C. 2002. "Factors influencing the choice of English as language of learning and teaching (LoLT) - A South African perspective". South African Journal of Education, 22 (2): 119-124.

GARDINER, M. 2008. Education in Rural Areas: Issues in Education Policy No.4, Johannesburg: CEPD.

HEDGE, MN. 2003. Clinical Research in Communication Disorders $\left(4^{\text {th }}\right.$ ed), Austin, TX: Pro-Ed.

HOWIE, S, E VENTER, S VAN STADEN, L ZIMMERMAN, C LONG, C DU TOIT, V SCHERMAN \& E ARCHER. 2008. PIRLS 2006 Summary Report: South African Children's Reading Achievement, Pretoria: Centre for Evaluation and Assessment. University of Pretoria.

HOWIE, SJ, C COMBRINCK, K ROUX, M TSHELE, G MOKOENA, N MCLEOD PALANE, 2016. PIRLS Literacy 2016: South African Highlights Report (Grade 4). Pretoria: Centre for Evaluation and Assessment, University of Pretoria.

HULME, CR \& MR JOSHI. 1998. Reading and Spelling: Development and Disorders. Lawrence Erlbaum Associates, Inc., Publishers, New Jersey.

JORDAAN, H. 2008. Intervention for bilingual language impaired children: An international survey. Folia Phoniatrica et Logopaedica, 60(2): 97-105.

LANGUAGE IN EDUCATION POLICY. 1997. Government of the Republic of South Africa: Government Notice No. 383, vol. 17997. www.education.gov.za/LinkClick.aspx?fileticket $=$ XpJ7gz4rPT0\%3D\&tabid $=390$ \&mid=1125 Accessed 10 December 2019.

LEKGOKO, O \& H WINSKEL. 2008. "Learning to read Setswana and English: Crosslanguage transference of letter knowledge, phonological awareness and word reading skills". Perspective in Education, 26 (4):57-73.

LE ROUX, M, S GEERTSEMA, H JORDAAN \& D PRINSLOO. 2017. Phonemic awareness of English second language learners. South African Journal of Communication Disorders 64(1), a164. Available from https://doi.org/10.4102/sajcd.v64i1.164 [Accessed 9 December 2019]

LINAN-THOMPSON, S. \& A ORTIZ. 2009. "Response to intervention and EnglishLanguage learners: Instructional and assessment considerations". Seminars in Speech and Language, 30 (2):105-120.

MABILETJA, MM. 2015. The transition to multilingual education in South African Schools. Doctoral thesis. Pretoria: UNISA.

MAKALELA, L., 2005. We Speak Eleven Tongues Reconstructing Multilingualism in

South Africa. In B Brock-Utne \& R Hopson, 2005 (Eds). Languages of Instruction for African Emancipation: Focus on Post-Colonial Contexts and Considerations. Dar es Salam: Mkuki na Nyota Publisher

MAKALELA, L. 2016. Bilingualism in South Africa: Reconnecting with Ubuntu Translanguaging, In: Garcia, O, A Lin \& S May (Eds), Bilingual and Multilingual Education. Encyclopedia of Language and Education (3rd ed.), Cham: Springer.

MENEGHETTI, C, B CARRETTI \& R DE BENI. 2006. Components of reading comprehension and scholastic achievement. Learning and Individual Differences, 16 (2006):291-301.

MERTENS, DM. 2005. Research and Evaluation in Education and Psychology: Integrating Diversity with Quantitative, Qualitative, and Mixed Methods $\left(2^{\text {nd }} \mathrm{ed}\right)$, Thousand Oaks: SAGE Publications. 
MULLIS, IVS, MO MARTIN, AN KENNEDY \& P FOY. 2007. PIRLS 2006 International Report: IEA's Progress in International Reading Literacy Study in Primary Schools in 40 Countries, Boston: TIMSS \& PIRLS International Study Centre.

NATIONAL INSTITUTE OF CHILD HEALTH AND HUMAN DEVELOPMENT, 2000. Report of the National Reading Panel, Teaching children to read: An evidencebased assessment of the scientific research literature on reading and its implications for reading instruction. Washington DC: U.S. Government Printing Office. Available from www.nationalreadingpanel.org. [Accessed: 3 July 2012.]

NEL, N \& H MULLER. 2010. "The impact of teachers' limited English proficiency on English second language learners in South African schools". South African Journal of Education, 30(4):635-650.

NYIKA, A.2015. Mother tongue as the medium of instruction at developing country universities in a global context. South African Journal of Science, 111(1/2):1-5. DOI: 0.17159/sajs.2015/20140005

OWENS, RE. 2004. Language Disorders: A functional approach to assessment and Intervention. (4th ed). Boston: Pearson Education, Inc.

PRETORIUS, E J. 2002. Reading ability and academic performance in South Africa: Are we fiddling while Rome is burning? Language Matters, 33(1):169-196.

PRETORIUS, EJ. 2000. "What they can't read will hurt them": Reading and academic Achievement. Innovation-Pietermaritzburg, 21(Dec); 33-41.

PRETORIUS, EJ \& R RIBBENS. 2005. Reading in a disadvantaged high school: Issues of accomplishment, assessment and accountability. South African Journal of Education, 25(3):139-147.

PROBYN, M. 2005. "Learning Science through the medium of English: What do Grade 8 learners say?" South African Linguistics and Applied Language Studies, 23 (4): 369-382.

PROBYN, M. 2001. “Teachers' voices: Teachers' reflections on learning and teaching through the medium of English as a second language". International Journal of Bilingual Education and Bilingualism, 4 (4):249-266.

REVISED NATIONAL CURRICULUM STATEMENT GRADES R-9 (SCHOOLS), 2002. Available from http://www.ibe.unesco.org/curricula/southafrica/sa_alfw_2002_eng.pdf . [Accessed: 10 February 2012]

SCHIAVETTI, N \& DE METZ. 2002, Evaluating Research in Communication Disorders. Boston: Allyn and Bacon.

STATISTICS SOUTH AFRICA, 2018. South African National Census of 2011. Pretoria: Statistics South Africa . Available from www.statssa.gov.sa. Accessed 24 February 2012

THE NATIONAL READING PANEL, 2000. Available from https://www.nichd.nih.gov/sites/default/files/publications/pubs/nrp/Documents/re port.pdf . Accessed 11 December, 2019.

NATIONAL READING STRATEGY. 2008. Department of Education of South Africa. Available from https://www.education.gov.za/Portals/0/DoE\%20Branches/GET/GET\%20Schools National_Reading.pdf?ver=2009-09-09-110716-507. [Accessed: 9 December 2019] 
VAN STADEN, S \& R BOSKER. 2014. "Factors that affect South African reading literacy achievement: Evidence from pre PIRLS", 2011. South African Journal of Education, 34 (3): art. 838, 1-9.

Watts-Taffe, S \& D Truscott. 2000. "Using what we know about language and literacy development for ESL students in the mainstream classroom". Language Arts, 77 (3): 258-265.

WIEDERHOLT, JL \& BR BRYANT. 2001. Gray Oral Reading Tests $\left(4^{\text {th }}\right.$ ed). Texas: ProEd Inc.

WILDSCHUT, Z, T MOODLEY \& S ARONSTAM. 2016. "The baseline assessment of Grade 1 learners' literacy skills". SA Journal of Childhood Education, 6 (1): 1-9.

WILSENACH, C. 2013. Phonological skills as predictor of reading success: An investigation of emergent bilingual Northern Sotho/English learners. Per Linguam, 29 (2):17-32. doi: http://dx.doi.org/10.5785/29-2-554

\section{BIOGRAPHICAL NOTES}

Munyane Mophosho is a senior lecturer in the Department of Speech Pathology and Audiology. She holds a PhD. She publishes in the area of Augmentative and Alternative Communication, multicultural and multilingual issues in Speech-Language Therapy and is a member of the International Association of Logopedics and Phoniatrics (IALP).

Katijah Khoza-Shangase, is an Associate Professor and former Head of Department in Speech Pathology and Audiology. She is a member of a number of committees and Boards at Discipline, School, Faculty, University, and National level. She has a number of peer-reviewed journal publications, technical/research reports/position papers, chapters, and a published co-edited book.

Lesedi L. Sebole is a Speech-Language Therapist. She works for the Department of Health. 